\title{
ESTIMATING CROP DENSITY FROM MULTI-SPECTRAL UAV IMAGERY IN MAIZE CROP
}

\author{
D. Stroppiana ${ }^{1, *}$, M. Pepe ${ }^{1}$, M. Boschetti ${ }^{1}$, A. Crema ${ }^{1,2}$, G. Candiani ${ }^{1}$, D. Giordan ${ }^{3}$, M. Baldo ${ }^{3}$, P. Allasia ${ }^{3}$, L. Monopoli ${ }^{4}$ \\ ${ }^{1}$ IREA CNR, Istituto per il Rilevamento Elettromagnetico dell'Ambiente, Consiglio Nazionale delle Ricerche, 20133 Milano, Italy - \\ (stroppiana.d, pepe.m, boschetti.m, crema.m, candiani.g)@itu.edu.tr \\ ${ }^{2}$ Department of Agricultural and Forestry scieNcEs (DAFNE), University of Tuscia, Via San Camillo de Lellis, 01100 Viterbo, Italy \\ ${ }^{3}$ IRPI-CNR, Istituto di Ricerca per la Protezione Idrogeologica, Consiglio Nazionale delle Ricerche, 10135, Torino, Italy - \\ (daniele.giordan, marco.baldo, paolo.allasia)@irpi.cnr.it \\ ${ }^{4}$ IBF Servizi S.p.a., 44037 Jolanda di Savoia, Ferrara, Italy - 1.monopoli@ibfservizi.it
}

Commission VI, WG VI/4

KEY WORDS: Maize field, Multi-spectral UAV, Vegetation Fractional Cover, image enhancement

\begin{abstract}
:
In this study we exploit UAV data for estimating Fractional Vegetation Cover (FVC) of maize crop at the early stages of the growing season. UAV survey with a MicaSense RedEdge multispectral sensor was carried out on July $13^{\text {th }}$, 2017 over a maize field in Italy; simultaneous RGB in situ pictures were collected to build a reference dataset of FVC over 15 ESU (Elementary Sampling Units) distributed over the field under investigation. The approach proposed for classification of UAV data is based on local contrast enhancement techniques applied to a vegetation index (NDVI-Normalized Difference Vegetation Index) to capture signal from small plants at the early development stage. The output fc map is obtained over grid cells over $70 \times 70 \mathrm{~cm}$ size. The approach proposed here, based on contextual analysis, reduced artefacts due to illumination conditions by better enhancing signal from vegetation compared to, for example, simple band combination such as vegetation index alone (e.g. NDVI). Validation accomplished by a point comparison between estimated (from UAV) and in situ measured FVC values provided $\mathrm{R}^{2}=0.73$ and $\mathrm{RMSE}=6 \%$.
\end{abstract}

\section{INTRODUCTION}

\subsection{Background}

Fractional Vegetation Cover (FVC) or Vegetation Fraction (VF) is defined as the ratio of the vertical projected area of vegetation canopy to the reference ground surface, expressed as fraction or percent (Purevdorj et al. 1998; Gitelson et al. 2002). FVC is an important variable related to many biophysical features, such as plant density, phenology, Leaf Area Index (LAI), yield and fraction of Absorbed Photosynthetically-Active Radiation (fAPAR) (Steven et al. 1986; Carlson et al. 1994; Owen et al. 1998); thus, it is frequently used to study and monitor ecosystem balance, soil erosion, climate change, vegetation degradation and desertification (Zribi et al., 2003; Lin and Qi, 2004; Jiapaer, Chen, and Bao, 2011). Therefore, the accurate estimation of FVC would have a significant impact on agricultural monitoring, ecological study and climate change analysis (Torres-Sánchez et al., 2014; Li and Zhang, 2015). In precision agriculture (PA), the assessment of FVC within a crop field is a first and crucial step, in order to address further objectives such as the detection and mapping of weeds (TorresSánchez et al., 2014; Stroppiana et al., 2018).

In this context, remote sensing (RS) techniques represent a valuable source of information to assess FVC. Advantages of RS technology include the synoptic view of the surface and the reduced cost per unit of area covered (Matese et al., 2015) compared to field surveys. Spaceborne and airborne platforms (also identified as high-altitude remote sensing instruments) have been the major source of observations for the optical properties of vegetation (e.g. Eerens et al., 2014; Pan et al., 2015). Despite the advantages offered by these systems, there are some limitations for PA applications, such as timeliness of the acquisitions, frequency and spatial resolution (Pinter et al., 2003), which can be too coarse for most of the fields in Italian family-owned farms. The recent introduction of a new platform for remote acquisition, Unmanned Aerial Vehicles (UAV), can overcome some of such limitations. Due to their flexibility, these low altitude systems can be considered complementary to high-altitude systems or even an alternative source of information over small area coverage (Huang et al., 2013). UAV advantages includes several features, such as i) the lack of an on-board pilot, ii) the ability to change flight altitude or to adjust the focal length, iii) the ability to fly on cloudy weather conditions, iv) the flexibility to mount different sensors. These features allow to reduce costs of vehicles and sensors, to acquire ultra-high spatial resolutions (pixels with GSD of few centimetres or even millimetres), to enhance and optimize revisiting times by scheduling acquisitions with farmers (Klemas 2015), thus helping to catch critical stages during the penological cycle of rapid growing crops (Hunt et al., 2010).

In recent years, UAV have been successfully used in PA objectives. These includes crop status and vigor, stress and disease conditions (Zarco-Tejada, González-Dugo, and Berni, 2012), crop bio-physical parameters such as canopy cover, Leaf Area Index, chlorophyll and nitrogen content (Torres-Sánchez et al., 2014), invasive weed presence (Peña et al., 2013) and potential yield (Stroppiana et al., 2015). Among FVC

\footnotetext{
* Corresponding author
} 
assessment from UAV, there are several studies which include monitoring of fractional vegetation cover variation of winter wheat ( $\mathrm{Li}$ et al., 2012), multi-temporal mapping of the vegetation fraction in early-season wheat fields (Torres-Sánchez et al., 2014), estimates of fractional vegetation cover in alpine grassland (Chen et al., 2016), estimation of vegetation fraction in oilseed rape (Fang et al., 2016) and multi-temporal monitoring of soybean vegetation fraction (Yun et al., 2016)

\subsection{Objectives}

The main objective of this study is to investigate UAV data on a real case scenario, cereal crop in a 56 ha field, in order to collect swift spatial explicit information on plant presence at early maize phenological stage as a support for tactic and strategic site specific agro-management. Therefore, we have two main objectives: i) to demonstrate the feasibility of UAV data for PA applications and ii) define an appropriate methodological workflow to efficiently process UAV data.

Regarding the first aim, the application in PA framework, the detection of vegetation presence and density (FVC) is fundamental for i) the provision of an indicator of germination efficiency and weed presence for tactic within-season management fertilisation and weed control and ii) collection of indirect mapping of soil properties (texture and fertility) for strategic planning such as smart scouting of soil sampling and to define future soil management practises.

Regarding the exploitation of UAV data in real case conditions characterised over a very wide field, we wanted to investigate and address problems related to different illumination condition in the aerial imagery. This aspect is fundamental in order to automatize plant presence detection minimizing errors due to sensor characteristics and changes in reflectance due to instrument, target and illumination geometry changes and artefacts generated in the ortho-mosaic production exploiting Structure From Motion (SFM).

\section{STUDY SITE AND DATA ACQUISITION}

\subsection{Study area and crop conditions}

The experiment took place in the commercial farm Bonifiche Ferraresi S.p.A. (BF) in its estate of Jolanda di Savoia (Ferrara). $\mathrm{BF}$ is the largest Italian farm, owing a whole of 6500 ha, in different estates, mainly located in three provinces in Italy: Ferrara (North-Eastern Italy), Arezzo (Central Italy) and Oristano (Sardinia). In the different estates, several crops are cultivated: rice, maize, durum and soft wheat, barley, sugar beet, alfalfa, soybean, horticultural plants, medicinal plants and fruit, which are distributed throughout the national territory. BF is interested in the development and application of innovative farming techniques, including PA, and holds a lot of geospatial data (e.g. soil maps, soil resistivity, yield maps), it hosted CNR experimental activities at Jolanda di Savoia estate $\left(11.95210^{\circ} \mathrm{E}\right.$, $44.85920^{\circ} \mathrm{N}$ ), which is a farm of 3800 ha (fig.1).

The site is located in a flat reclaimed land, near the river Po delta, around $4 \mathrm{~m}$ below the sea level, characterised by very variable soil conditions, with several palaeochannels. The field under investigation, coded 467 (highlighted in fig.1), of around $\sim 56$ ha, was cultivated according to the farm practice and sown as second crop cycle on June $24^{\text {th }}, 2017$, with silage maize.
The soil and resistivity maps are shown in Figure 2, the majority of the field is characterized by clay soils (namely Forcello, and coded FOR1 in Figure 2a) which are rich in organic substance, with thin peaty levels (10 $\mathrm{cm}$ maximum) and sometimes presenting small calcium and chalk carbonate concretions.

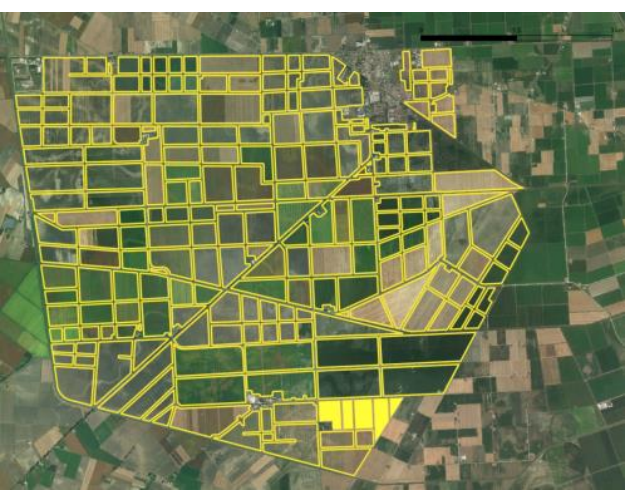

Figure 1. Jolanda di Savoia estate, the field of experiment (ID $467)$ is highlighted in yellow.

The other parts of the field are characterized by: FOR2, which is the same type of soil but poorly drained (this is the reason why, as shown in fig. 1 and 2 , the field is subdivided into parcels by drains, see also the resistivity map Figure $2 b$ ); and only a small portion by a more silty soil related to channels (MSF1), but which is out of the overflight coverage (only the northern part of the field, see Figure 6).

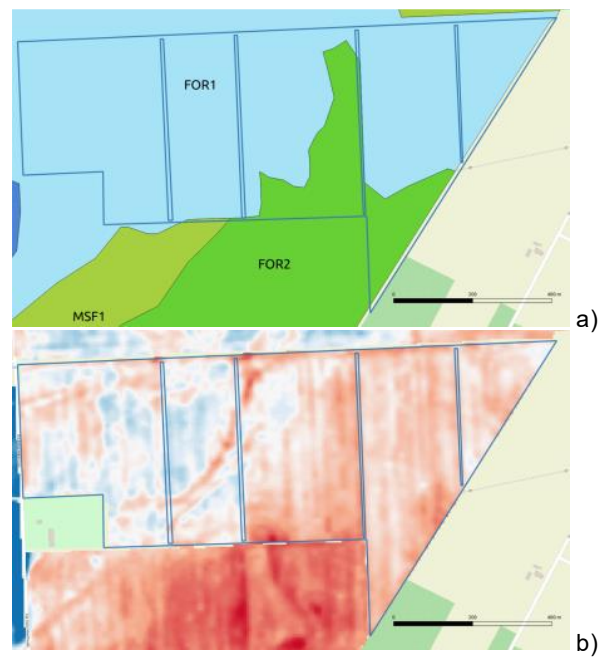

Figure 2. a) Soil map of field 467: soil codes are explained in the text. b) Resistivity map of field 467; it is visible, more in

detail as respect to the soil map, the poorly drainage soil conditions (low resistivity depicted in red).

At the time of surveying, maize crop conditions (i.e. crop establishment, density and weed presence) were characterized by a high rate of patchiness as mainly due to: the soil moisture variability and the time lapse in management due to the size of the field, in fact, sowing 56 ha took 4-5 days. On the day of the survey, within the field 467 , maize phenology stages varied respectively from 1st leaf stage, i.e BBCH 11 (Lancashire et al., $1991)$, to 4 th leaf unfolded stage $(\mathrm{BBCH}=14)$, with a maximum plant height of about $25 \mathrm{~cm}$. The range of crop conditions is depicted in Figure 3. 


\subsection{Data acquisition}

On July $13^{\text {rd }}$, 2017 in situ observations of crop cover and density were collected over a set of 15 elementary sample units (ESU) covering an area of $1 \mathrm{~m}^{2}$ each to fully characterize the variability of crop conditions (Figure 3) of field 467. During field survey each ESU was observed by four adjacent photos taken at nadir over the crop canopy with a SONY cybershot DSC HX20C RGB camera. Each photo embraced an area of 0.5 $\mathrm{m}^{2}$ identified on the ground by a square wooden frame positioned over the maize crop and included in the camera shot (see example in Figure 3), to be used as reference data.
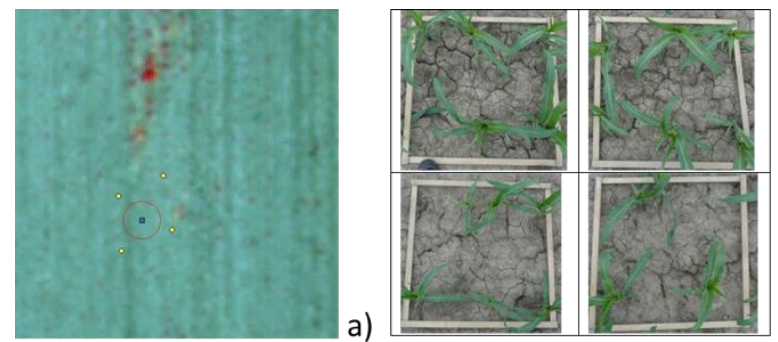

Figure 3. a) Example of in situ measurement of FVC by taking four photos (yellow dots) at each ESU identified by the central coordinates (blu square); b) photo taken at one ESU with reference wooden frame.

UAV data were acquired on the same day of field survey over field 467 with V-Tail prototypal fixed-wing RPAS at around 75 $\mathrm{m}$ above ground level, with a GSD of $7 \mathrm{~cm}$. The vehicle, XUAV Talon assembled and modified by IRPI-CNR, mounting a multi-spectral MicaSense RedEdge sensor. The sensor acquires images in five spectral bands: blue, green, red, red edge, and Near Infrared (NIR). The sensor was calibrated using a reference panel before and after the images acquisition. A flight planner defined the UAV trajectory and the acquisition of the multi-spectral sensor was temporized, with a new image every 5 seconds.

The overflight did not fully cover the field extension, since the weather conditions where suddenly changing during the day, causing important changes in radiometry.

\section{METHODS}

\subsection{Classification of in situ RGB photos}

In situ RGB photos were classified by a supervised approach with training pixels collected by expert photointerpretation. We defined two classes (soil and vegetation) and applied a Support Vector Machine (SVM) classification algorithm in HARRIS ENVI® software (Figure 4). The two-class thematic output map allowed us to estimate the crop fractional vegetation cover (FVC [\%]) inside each sample area of $0.5 \mathrm{~m}^{2}$ identified visually by the wooden frame.

The FVC value assigned to ESU is the average of the FVC s estimated from the set of four RGB photos. In situ FVC at the $15 \mathrm{ESU}$ varied in a range from 0.0 (soil) to 0.30 (most vegetated areas). This dataset was used as a reference data for comparison with FVC estimated from UAV multispectral imagery.
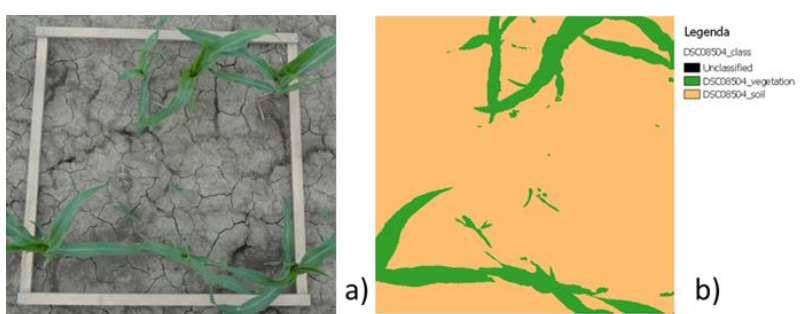

Figure 4. a) In situ RGB photo and b) SVM classification for the estimation of ground fractional vegetation cover; only pixels inside the $0.5 \mathrm{~m}^{2}$ frame are shown.

\subsection{UAV imagery processing}

UAV images were processed with Pix4D software for orthoprojection to obtain the ortho-mosaic in the five spectral bands of the MicaSense RedEdge sensor (Figure 1) exploiting SFM technique and obtaining a GSD of $7 \mathrm{~cm}$. PiX4D has a dedicated processing chain developed for multi-spectral datasets. The software is able to acquire both images taken during the flight and the bands calibration images. A set of spectral indices was computed from the multi-spectral image: NDVI (Normalized Difference Vegetation Index), RGRI (Red Green Ratio Index), NDRE (Normalized Difference Red Edge), SAVI (Soil Adjusted Vegetation Index), NDRI (Normalized Difference Red/Green Redness Index). Preliminary analysis of correlation between the vegetation indices and in situ FVC pointed out that NDVI was the most suitable index in our case study. This is an expected result because NDVI shows a strong sensitivity at early crop stages due to the contrast between background (soil) and plant presence.

\subsection{Estimation of fractional vegetation cover}

A fractional vegetation cover map was obtained from UAV ortho-mosaic by exploiting an approach based on the enhancement of the local contrast in NDVI images.

A median filter was used over a moving window (Kernel) to enhance contrast of NDVI in regions where maize plants are smaller than the average; these regions in fact would not be captured with a simple thresholding step with a global threshold values over the image.

Hence, the map, representing the spatial distribution of crop FVC was computed with the following steps:

1. Resampling NDVI to $70 \mathrm{~cm}$ spatial resolution ( $10 \times 10$ image pixel grid cells);

2. Computing median filter from full resolution NDVI with a kernel size of 21 x 21 image pixels;

3. Differencing the two layers described above to enhance local contrast (NDVI-local filter);

4. Thresholding the difference layer so that vegetated pixels are those with difference $\geq 0.05$;

5. Computing fractional vegetation cover (FVC) as the proportion of vegetated pixels over total number of pixels within each $10 \times 10$ grid cell.

The final output FVC map is therefore the fractional vegetation cover at a spatial resolution of $70 \mathrm{~cm}$; it ranges in $0-1$ over each grid cell. 


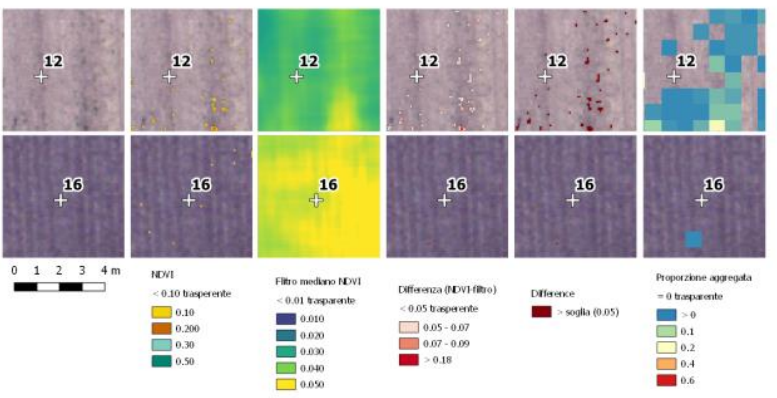

Figure 5. The sequence of steps listed in 3.3 for two ESU: RGB images over the area (column 1), overlay of full resolution pixels with NDVI $>0.1$ (column 2), NDVI median filter output (column 3), difference between NDVI and median filter (column 4), pixels that satisfy the conditions $>0.05$ (Column 5) and FVC map aggregated over 10x10 pixels cell size $(\sim 70 \mathrm{~cm})$ (Column 6).

\subsection{Validation}

The accuracy of the FVC map was assessed by comparison with in situ FVC estimates obtained at the location of the $15 \mathrm{ESU}$; the centre of each ESU was used to locate over the aggregated FVC map. Estimated and in situ FVC values were compared at each ESU and regression analysis metrics were computed to quantify the difference between the two values.

\section{RESULTS}

\subsection{Multi-spectral ortho-mosaic}

The multi-spectral ortho-mosaic is shown in Figure 6. The image highlights the variability of crop conditions within the portion of the field overflown by the UAV survey. In the image change in reflectance are due to both soil properties (see resistivity anomaly in Figure $2 \mathrm{~b}$ ) and residual artefacts due to illumination conditions (sun illumination varying during the overflight). These artefacts are not compensated during preprocessing and mosaicking. Indeed, processing of UAV imagery poses several issues which are still unsolved by traditional photogrammetric processing approaches (Whitehead and Hugenholtz, 2014).

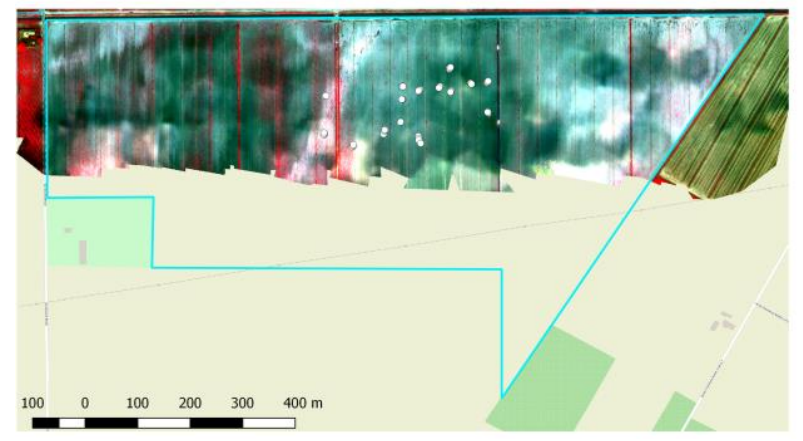

Figure 6. Multispectral ortho-mosaic displayed as RGB false colour composite $(\mathrm{R}=\mathrm{NIR}, \mathrm{G}=\mathrm{red}, \mathrm{B}=$ green) with overlaid $\mathrm{ESU}$ positions (white dots) and field borders (cyan polygon).

Figure 7 shows profiles in the five spectral bands of the UAV multi-spectral image over the ESUs. Spectral profiles were extracted by considering a circular Region Of Interest (ROI) centred at the ESU location and by averaging the pixels values for each band. The radius of the ROI was varied in the range $[0.1-1.0 \mathrm{~m}]$ to analyse the variability of the output spectral profile as a function of the portion of image extracted for computing average reflectance; variability is due to spatial changes and heterogeneity of the target surface. In the figure greater changes are observed over ESU where crop was more developed $(2,3,4)$; by changing ROI size a more variable proportions of vegetated and soil pixels fall within the ROI.

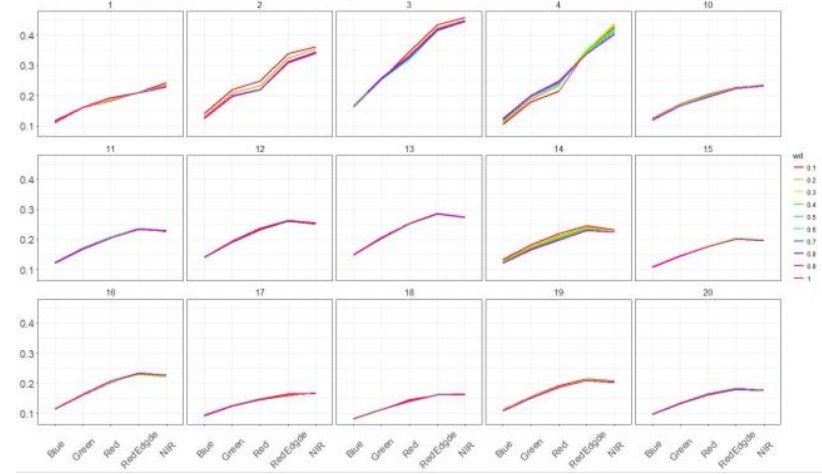

Figure 7. Spectral profiles in the five bands of the RedEdge sensor over the ESU (panels) as a function of the ROI size used for extracting and averaging reflectance.

\subsection{Fractional vegetation cover map}

The FVC map obtained following the procedure described in 3.3 is shown in Figure 8.d; the output product is zoomed in over the portion of the maize field where ESU were located. Theoretically, fractional cover ranges between 0.0 and 1.0 showing the proportion of vegetated pixels within each cell $(\sim$ $70 \times 70 \mathrm{~cm})$. Since the growing season was at the early stages, actual FVC values were generally below 0.4 with a clear difference between the eastern and western portions of the field. Indeed, these two regions of the field were sown on different dates: the left (western) part was sown earlier compared to the right (eastern) as confirmed by greater values of FVC (green tones in the map). Greater FVC values were observed along the drain channels were natural vegetation grows more vigorously.

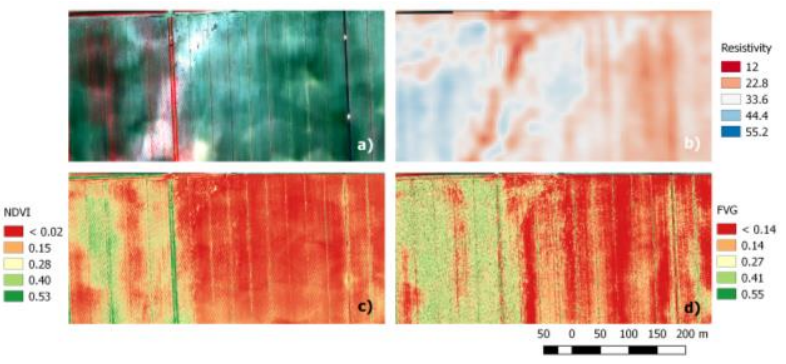

Figure 8. Results over the portion of the field were ESUs are located: a) Multispectral ortho-mosaic displayed as RGB false colour composite ( $\mathrm{R}=\mathrm{NIR}, \mathrm{G}=\mathrm{red}, \mathrm{B}=$ green $)$; b) soil resistivity; c) NDVI; d) FVC map.

In the same figure we compared FVC map (panel d) with NDVI (panel c), soil resistivity map (panel b) and false colour composite of the UAV multi-spectral image (panel a). The NDVI layer shows spatial patterns due to illumination artefacts and soil characteristics, which strongly influence reflectance in the UAV ortho-mosaic; an evident example is the western part 
of the image (maize sown earlier) where the output FVC product displays more homogeneous results compared to NDVI. Finally, looking at Figure 8a and Figure 8b and comparing the UAV ortho-mosaic reflectance with the spatial variability of soil resistivity better highlights patterns due to changes in soil characteristics. Spatial variability of soil characteristics in fact is a key factor influencing crop development. Therefore, processing based on image enhancement produces FVC estimates consistent with crop conditions observed in the field and can be used to extract information (vegetation presence and density related to sowing date, plant mortality and soil fertility) useful for field agronomic management.

\subsection{Validation}

Validation carried out at each ESU showed a suitable agreement, with $\mathrm{R}^{2}=0.73$ and RMSE $=6 \%$ (Figure 9). The best agreement was obtained over the sample units with the lowest crop density (fractional vegetation cover).
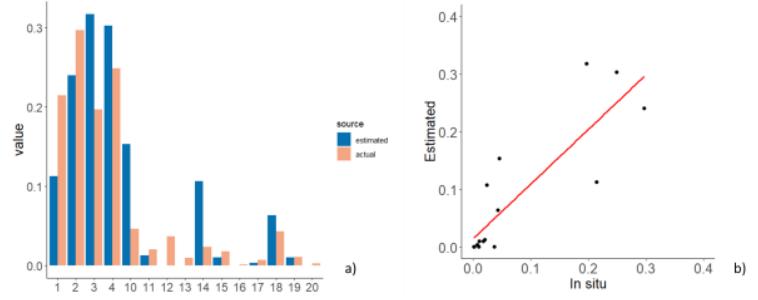

Figure 9. Results of the validation of fractional vegetation cover maps over the $15 \mathrm{ESU}$ : estimated and actual FVC values for each ESU (a) and regression between estimated and in situ FVC values (b).

This output information could be input layer for, by example, Variable Rate Technology fertilization in the framework of PA field management practises. Resampling over larger cell proposed here is suitable for enhancing the signal of less developed plants and reducing image noise. In a framework of operational VRT applications, hyper-spatial information produced by full resolution UAV imagery could be redundant when used as input at the scale of the Management Unit Zones (MUZ).

\section{CONCLUSIONS}

A fractional cover maps over a maize field was obtained from multi-spectral UAV image. UAV survey was carried out at the early stages of the crop growing season for applications of VRT technologies for crop management. UAV acquisitions over areas require multiple overpasses and the reconstruction of ortho-mosaic from different frames, which are acquired with different instrument, target and illumination geometry. This condition results problematic showing artefacts in the image that could reduce the full exploitation of spectral information from multi-spectral data.

The approach applied for deriving FVC map is based on local contrast enhancement techniques applied to NDVI (Normalized Difference Vegetation Index) both to capture signal also from small plants and to reduce the false patterns due to other factors (e.g. illumination and mosaicking). The variability of crop conditions observed and measured during the synchronous field campaign was confirmed by the output FVC map. Accuracy evaluated by comparison with in situ FVC values derived from supervised classification of nadir RGB pictures shows satisfactory results $\left(\mathrm{R}^{2}=0.73\right.$ and $\left.\mathrm{RMSE}=6 \%\right)$.

\section{REFERENCES}

Carlson, T.N., Gillies, R.R., Perry, E.M., 1994. A method to make use of thermal infrared temperature and NDVI measurements to infer surface soil water content and fractional vegetation cover. Remote Sensing Reviews, 9, 161-173. doi.org/10.1080/02757259409532220.

Chen, J., Yi, S., Qin, Y., Wang, X., 2016. Improving estimates of fractional vegetation cover based on UAV in alpine grassland on the Qinghai-Tibetan Plateau. International Journal of Remote Sensing, 37(8), 1922-1936. doi.org/10.1080/01431161.2016.1165884.

Eerens, H., Haesen, D., Rembold, F., Urbano, F., Tote, C., Bydekerke, L., 2014. Image time series processing for agriculture monitoring. Environmental Modelling \& Software, 53, 154-162. doi.org/10.1016/j.envsoft.2013.10.021.

Fang, S., Tang, W., Peng, Y., Gong, Y., Dai, C., Chai, R., Liu, K., 2016. Remote Estimation of Vegetation Fraction and Flower Fraction in Oilseed Rape with Unmanned Aerial Vehicle Data. Remote Sensing, 2016, 8, 416. doi.org/10.3390/rs8050416.

Gitelson, A.A., Kaufman, Y.J., Stark, R., Rundquist, D., 2002. Novel algorithms for remote estimation of vegetation fraction. Remote sensing of Environment., 80, 76-87. doi.org/10.1016/S0034-4257(01)00289-9.

Huang, Y., Thomson, S. J., Hoffmann, W. C., Lan, Y., Fritz, B. K., 2013. Development and prospect of unmanned aerial vehicle technologies for agricultural production management. International Journal of Agricultural and Biological Engineering, 6(3), 1-10.

Hunt, E.R., Hively, W.D., Fujikawa, S.J., Linden, D.S., Daughtry, C.S.T., McCarty, G.W., 2010. Acquisition of NIRgreen-blue digital photographs from unmanned aircraft for crop monitoring. Remote Sensing, 2, 290-305. doi.org/10.3390/rs2010290.

Jiapaer, G., Chen, X., Bao, A. M., 2011. A Comparison of Methods for Estimating Fractional Vegetation Cover in Arid Regions. Agricultural and Forest Meteorology., 151(12), 16981710. doi.org/10.1016/j.agrformet.2011.07.004.

Klemas, V.V., 2015. Coastal and environmental remote sensing from unmanned aerial vehicles: An overview. Journal of Coastal Research, 31(5), 1260-1267. doi.org/10.2112/JCOASTRES-D-15-00005.1.

Lancashire, P.D., Bleiholder, H., Boom, T. Van Den, Langelüddeke, P., Stauss, R., Weber, E., Witzenberger, A., 1991. A uniform decimal code for growth stages of crops and weeds. Annals of Applied Biology. doi.org/10.1111/j.17447348.1991.tb04895.x

Li, B., Liu, R., Liu, S., Liu, Q., Liu, F., Zhou, G., 2012. Monitoring vegetation coverage variation of winter wheat by low-altitude UAV remote sensing system. Transactions of the Chinese Society of Agricultural Engineering, 28(13), 160-165. 
Li, X., Zhang, J., 2015. Derivation of the green vegetation fraction of the whole China from 2000 to 2010 from MODIS data. Earth Interactions, 20(8), 1-16. doi.org/10.1175/EI-D-150010.1 .

Lin, Z. S., X. Z. Qi., 2004. Vegetation Evolution with Degenerating Soil Ecology under Unequal Competition. Pedosphere 14(3), 355-361.

Matese, A., Toscano, P., Di Gennaro, S. F., Genesio, L., Vaccari, F. P., Primicerio, J., Belli, C., Zaldei, A., Bianconi, R., Gioli, B., 2015. Intercomparison of UAV, aircraft and satellite remote sensing platforms for precision viticulture. Remote Sensing, 7(3), 2971-2990. doi.org/10.3390/rs70302971.

Owen, T.W., Carlson, T.N., Gillies, R.R., 1998. An assessment of satellite remotely-sensed land cover parameters in quantitatively describing the climatic effect of urbanization. International Journal of Remote Sensing, 19, 1663-1681. doi.org/10.1080/014311698215171.

Peña, J. M., Torres-Sánchez, J., de Castro, A. I., Kelly, M., López-Granados, F., 2013. Weed mapping in early-season maize fields using object-based analysis of unmanned aerial vehicle (UAV) images. PLoS ONE, 8(10), e77151. doi.org/10.1371/journal.pone.0077151.

Pinter Jr, P. J., Hatfield, J. L., Schepers, J. S., Barnes, E. M., Moran, M. S., Daughtry, C. S., Upchurch, D. R., 2003. Remote sensing for crop management. Photogrammetric Engineering \& $\begin{array}{lll}\text { Remote } & \text { Sensing, 69(6), 647-664. }\end{array}$ doi.org/10.14358/PERS.69.6.647.

Purevdorj, T. S., Tateishi, R., Ishiyama, T., Honda, Y., 1998. Relationships between percent vegetation cover and vegetation indices. International Journal of Remote Sensing, 19(18), 35193535. doi.org/10.1080/014311698213795.

Steven, M.D., Biscoe, P.V., Jaggard, K.W., Paruntu, J., 1986. Foliage cover and radiation interception. Field Crops Research, 13, 75-87. doi.org/10.1016/0378-4290(86)90012-2.

Stroppiana, D., Migliazzi, M., Chiarabini, V., Crema, A., Musanti, M., Franchino, C., Villa, P., 2015. Rice yield estimation using multispectral data from UAV: A preliminary experiment in northern Italy. In 2015 IEEE International Geoscience and Remote Sensing Symposium (IGARSS), 46644667. IEEE. Doi.org/10.1109/IGARSS.2015.7326869.

Stroppiana D., Villa, P., Sona, G., Ronchetti, G., Candiani, G., Pepe, M., Busetto, L., Migliazzi, M., Boschetti, M., 2018. Early season weed mapping in rice crops using multi-spectral UAV data. International Journal of Remote Sensing, 39(15-16), 5432-5452. doi.org/10.1080/01431161.2018.1441569.

Torres-Sánchez, J., Peña, J.M., de Castro, A.I., LópezGranados, F., 2014. Multi-temporal mapping of the vegetation fraction in early-season wheat fields using images from UAV. Computers and Electronics in Agriculture, 103, 104-113. doi.org/10.1016/j.compag.2014.02.009.

Whitehead, K., Hugenholtz, C.H., 2014. Remote sensing of the environment with small unmanned aircraft systems (UASs), part 1: A review of progress and challenges. Journal of Unmanned Vehicle Systems. 02. 69-85. doi.org/10.1139/juvs-2014-0006.
Yun, H.S., Park, S.H, Kim, H.J., Lee, W.D, Lee, K.D, Hong, S.Y., Jung, G.H., 2016. Use of Unmanned Aerial Vehicle for Multi-temporal Monitoring of Soybean Vegetation Fraction. Journal of Biosystems Engineering, 41(2), 126-137. doi.org/10.5307/JBE.2016.41.2.126.

Zarco-Tejada, P.J., González-Dugo, V., Berni, J.A. 2012. Fluorescence, temperature and narrow-band indices acquired from a UAV platform for water stress detection using a microhyperspectral imager and a thermal camera. Remote Sensing of Environment, 117, 322-337. doi.org/10.1016/j.rse.2011.10.007.

Zribi, M., Hégarat-Mascle, S.L., Taconet, O., Ciarletti, V., Vidal-Madjar, D., Boussema, M.R., 2003. Derivation of Wild Vegetation Cover Density in Semi-Arid Regions: ERS2/SAR Evaluation. International Journal of Remote Sensing, 24 (6): 1335-1352. doi.org/10.1080/01431160210146668. 